\begin{tabular}{|c|c|c|c|c|c|}
\hline 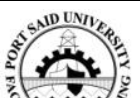 & \multicolumn{4}{|c|}{$\begin{array}{l}\text { PORT SAID ENGINEERING RESEARCH JOURNAL } \\
\text { Faculty of Engineering - Port Said University }\end{array}$} & \\
\hline 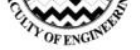 & Volume 18 & No. 2 & September2014 & pp:32 : 41 & \\
\hline
\end{tabular}

\title{
Fault response of grid-connected squirrel cage wind-power induction generator
}

\author{
Nagwa F. Ibrahim ${ }^{I}$, Ali. H. Kasem Alaboudy ${ }^{1}$, Hossam M. Attia ${ }^{l}$, and Sobhy S. Desouky ${ }^{2}$
}

\begin{abstract}
This paper presents fault response of squirrel cage induction generator through grid connected of wind power. Thus, the Squirrel Cage Induction Generator (SCIG) is connected to an infinite bus through delta grounded wye transformer, transmission line and load. The capacitance compensation will be installed. The simulation model of grid connected squirrel cage wind power induction generator is discussed in the stationary reference frame using (MATLAB/SIMULINK). Simulations results have been investigated by various symmetrical and unsymmetrical faults. The fault is applied to the induction generator terminals. The paper introduces various types of algorithms to calculate the currents, frequencies and voltages in order to protect the wind driven induction generator connected to a power system grid.
\end{abstract}

Keywords - squirrel cage induction generator (SCIG), short-circuit, fault, protection Algorithms

\section{INTRODUCTION}

Recently, it is realized that world's oil supplies would not last forever and that remaining supplies should be conserved for petrochemical industry. Other energy resources like coal and nuclear energy present serious environmental problems. These are the motivations behind considering the new energy resources like wind energy, solar energy, falling water energy, bio-mass energy and other energy alternative energy. The wind is a free, clean and inexhaustible energy source [1]. due to its reduced cost, its brushless rotor, absence of separate dc source for excitation, ruggedness, and ease of control and maintenance, squirrel cage-type induction generators have emerged as suitable candidates for wind turbine generation. This is because it bears the fluctuating wind and it cannot afford the fault transient, due to hauled to the reactive power, and increasing number of relatively (SCIG) connected to the power grid at the distribution level [2]. The induction generators require essentially no controls other than a contactor to connect the machine. The induction generator, like a synchronous generator, requires excitation in order to produce voltage and become a source of electrical power [3].

\footnotetext{
${ }^{1}$ Electrical Power, and Machines Department, Faculty of Industrial Education, Suez University, Suez, Egypt, E-mail: eng.nagwafadl@yahoo.com alihkasem@yahoo.com

hossam65eg@yahoo.com

${ }^{2}$ Electrical Power, and Machines Engineering Department, Faculty of Engineering, port said University, Egypt, E-mail:

sobhyserry@yahoo.com
}

The operation of connecting an induction generator with the utility grid is simpler than that of synchronous generator. Under fault conditions, the current drawn by the induction generator to provide its excitation is frequently reduced. For a three phase fault, current cannot be transferred past the fault point of the induction generator, therefore the unit loses its excitation. If the unit is provided with capacitors, fault would quickly cause these to be discharged, again resulting in removal of excitation from the generator [4]. Protection of an induction generator based system differs significantly from a similar plant with a synchronous generator. Many traditional protective devices are unnecessary because of the fundamental differences in performance between induction and synchronous generators. Examples of relays are not required for an induction generator, such relays included loss of excitation, synchronizing check and voltage balance [4]. Former studies were of limited range and, at the same time, they mostly focused on the protection of doubly fed induction generators (DFIG) e.g., crowbar protection is a well know method in (DFIG) protection. Sattar et.al. [5] presented the crowbar and its usage when it comes to protecting the rotor converter against short circuit current during faults. They found that the stator and rotor transient current decay rapidly to value with amplitude less than one pu and rotor circuit is properly protected when the crowbar is activated. Krisztina [6] presented dump resistor protection the crowbar and dump resistor and using it to protect the rotor converter against short circuit current during faults. By Comparing crowbar to dump resistor, it is concluded that the dump resistor is best than that crowbar protection [5]. Microprocessor relay is a well-known method in (SCIG). Attia [7] presented the protection of the induction generator against short circuit current, under voltage, over/under frequency and negative sequence 
during faults and presented the new frequency protection algorithm that based on quadratic froms of voltage signal sample which was measured at the generator terminals. In order to overcome the difficulty described previously, this work studies the transient response of grid connected SCIG subjected to short circuit fault at the generator terminals of wind turbine. A simulation model of wind turbine with SCIG is investigated and the protection schemes of the system are described. In addition, four sample methods are employed to apply symmetrical and unsymmetrical faults, and design the protection schemes of the SCIG with the wind turbine.

\section{SYSTEM UNDER STUDY}

The reference frame is chosen to be the mathematical model of induction generator. It simulates various abnormalities at the terminals of a loaded induction generator connected directly to an infinite bus. This system is attributed to the studies of the various abnormalities occurring at point $f$ of the system shown in Figure 1.

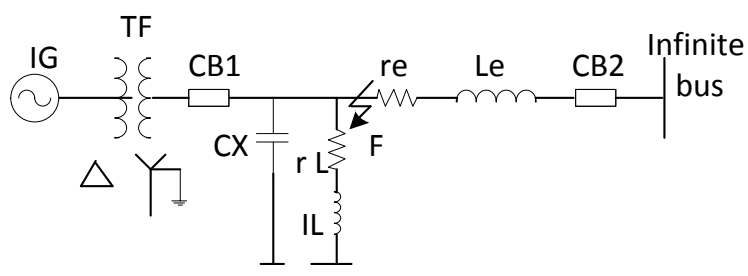
IG: induction generator
rL and IL: local load
Tf: transformer
re and le: transmission
line resistance and inductance
Cx: shunt capacitor
CB1-CB2 are circuit breakers

Figure1. Induction generator a system

The induction generator, capacitor, and load may be grounded. The three-phase transformer bank is connected in delta - grounded wye. The magnetizing current and losses are neglected. It is represented by series resistance and inductances. A $125 \mathrm{hp}$ squirrel cage induction generator is used as the test model whose constants, referred to its rated three-phase apparent power 93.25KVA, and rated line-to-line voltage $460 \mathrm{~V}$, are $\mathrm{Rs}=0.0228, \quad \mathrm{Rr}=0.0297, \quad \mathrm{LLs}=0.0809, \quad \mathrm{LLr}=0.119$, $\mathrm{Lm}=4 \mathrm{p}-\mathrm{u}$. [7].

\section{PROTECTION ALGORITHMS}

The present algorithm for the negative sequence, frequency, and current based on symmetrical and unsymmetrical components can be used to send certain signal to the device to protect the induction generator in the system against over current, over-under frequency, under voltage, and overheating [5].

\subsection{ALGORITHM of OVER CURRENT PROTECTION}

The expression of the algorithm is based on four equally spaced samples (90) degrees apart. A sine wave current signal is assumed. The chosen approach for identifying the rms value from the real time samples of a signal offers an almost complete rejection of decaying DC components. It is based on two finite impulse-response digital filters. The two filter outputs, $\mathrm{S}$ and $\mathrm{C}$, at any instant of time provide two cartesian-coordinate phasor components of the input. They are defined as:

$$
\begin{aligned}
& S=i_{1}+i_{2}-i_{3}-i_{4} \\
& C=i_{1}-i_{2}-i_{3}+i_{4}
\end{aligned}
$$

where $i_{1}, i_{2}, i_{3}$ and $i_{4}$ are four equally spaced samples. It can be easily shown that the rms value of a sine wave I is given by Equations $(3,4)$ this rms is considered as the input to the digital relay, Figures 2, 3.

$$
\begin{aligned}
& i_{P}=\sqrt{\left(S^{2}+C^{2}\right) / 16} \\
& \theta=\tan (C / S)
\end{aligned}
$$

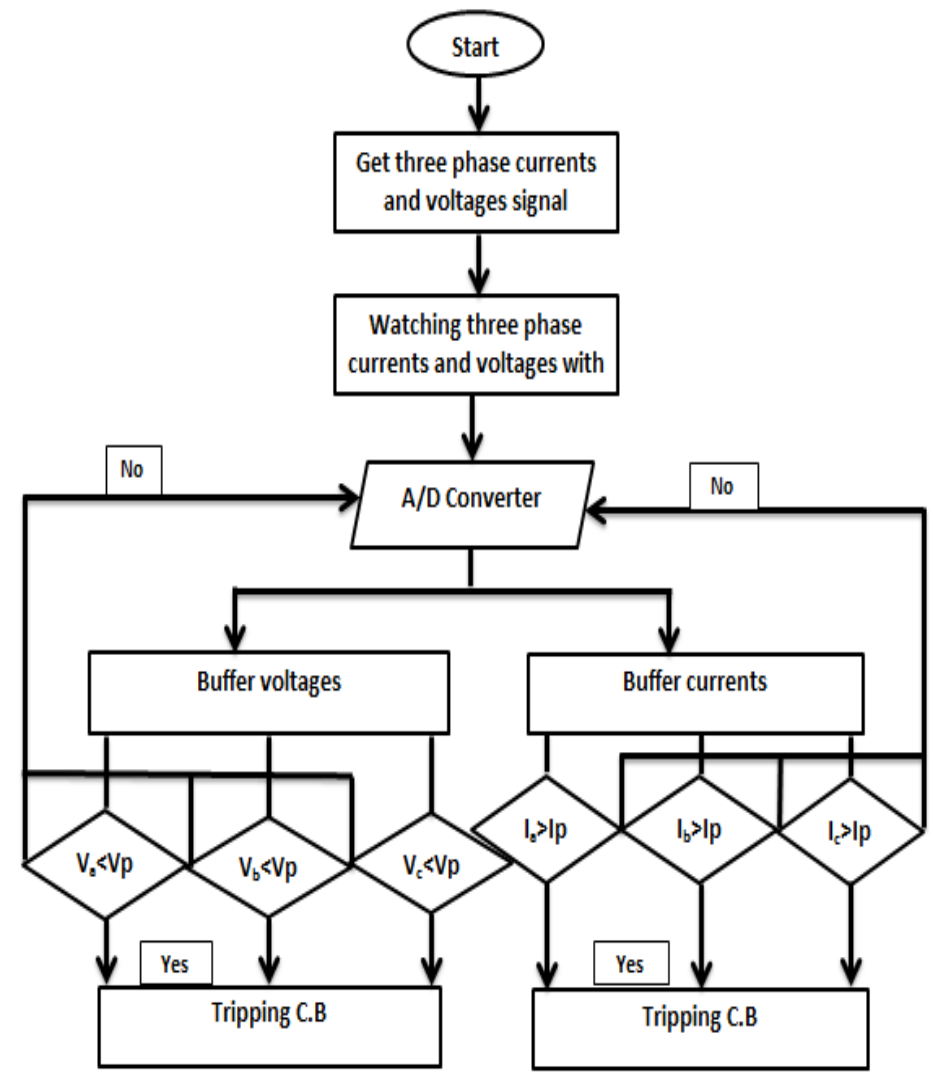


Figure2. Flow-Chart of Digital Relay

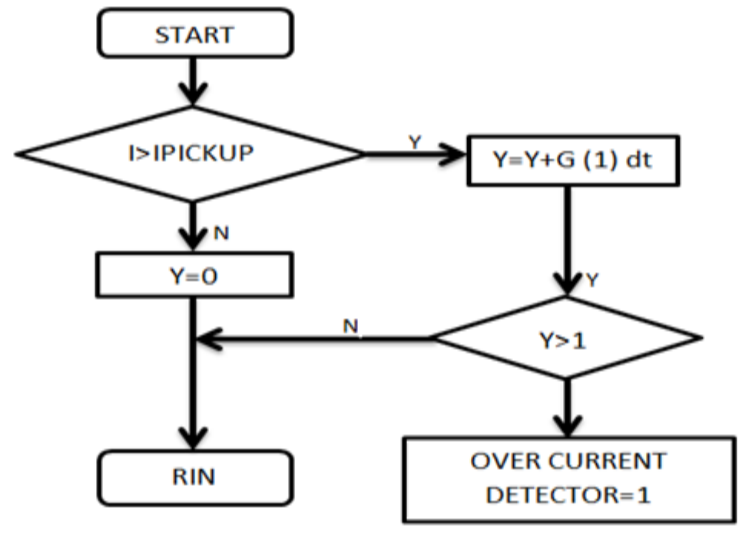

Figure3. Flow-chart of over-current relay

\subsection{ALGORITHM OF NEGATIVE SEQUENCE PROTECTION}

The algorithm expression is based on symmetrical components theory. The relation between the phase rms quantities and the symmetrical components is given by

$I_{012}=1 / 3|A|\left|I_{a b c}\right|$

where

$\left|\begin{array}{lll}I_{0} & 12\end{array}\right|=\left|\begin{array}{l}I_{0} \\ I_{1} \\ I_{2}\end{array}\right|$

$\equiv$ Zero, positive and negative sequence components (012) vectors

$$
\begin{gathered}
|A|=\left|\begin{array}{ccc}
1 & 1 & 1 \\
1 & a & a^{2} \\
1 & a^{2} & a
\end{array}\right| \\
\left|I_{a b c}\right|=\left|\begin{array}{c}
I a \\
I b \\
I c
\end{array}\right|
\end{gathered}
$$

and

$$
a=\operatorname{Exp}(j 2 \pi / 3) \quad a^{2}=\operatorname{Exp}(j 4 \pi / 3)
$$

For real time applications, the relationship between the symmetrical components and sampled data of the instantaneous phase quantities is considered. The relation between the instantaneous symmetrical components, as (time domain representation) is given by:

$\left|\begin{array}{l}I_{0}(t) \\ I_{1}(t) \\ I_{2}(t)\end{array}\right|=\frac{1}{3}\left|\begin{array}{ccc}i_{a}(t)+ & i_{b}(t)+ & i c(t) \\ i_{a}(t)+ & i_{b}(t-2 T / 3)+ & i_{c}(t-T / 3) \\ i_{a}(t)+ & i_{b}(t-T / 3)+ & i_{c}(t-2 T / 3)\end{array}\right|$

where $\mathrm{T}$ is the time period of the power frequency $\omega$. based on Equation (2). The technique of overcurrent algorithm is adapted for calculating the rms values of the negative sequence components for an unbalanced 3phase system. Each sample of the four instantaneous samples required for signal identification consists of three instaneous signals (one for each phase) displaced in time by 120 degrees $(\mathrm{T} / 3 \mathrm{sec})$. Then, four negative sequence instantaneous samples are presented: $i_{21}, i_{22}, i_{23}$, $i_{24}$ the rms values of the negative sequence components are then determined in terms of S2 and $\mathrm{C} 2$, and Ip as follows:

$$
\begin{aligned}
& S_{2}=i_{21}+i_{22}-i_{23}-i_{24} \\
& C_{2}=i_{21}-i_{22}-i_{23}+i_{24} \\
& I p=\sqrt{\left(S^{2}+C^{2}\right) / 16}
\end{aligned}
$$

\subsection{ALGORITHM OF FREQUENCY PROTECTION}

A general algorithm expression is a quotient of quadratic forms (QQF) of signal samples. The following input voltage signal representation is assumed. Equation (13), can be Quadratic forms of a signal V denoted here as kf, and may be expressed using matrix notation as in Equations (14-16).

$$
\begin{aligned}
& V(t)=v \cos (\omega t+\phi) \\
& K f(n)=\sum_{k=0}^{N-1} \sum_{m=0}^{N-1} b_{k m} v_{n-k} v_{n-m}=v^{T} B v \\
& v^{T}=\left|v_{n} v_{n-1} \ldots \ldots v_{n-N+1}\right| \\
& \boldsymbol{B}=\left\{\boldsymbol{b}_{k m}\right\}
\end{aligned}
$$

where;

$\mathrm{N}$ : number of sampling rate

Vn: a voltage signal sample at the discrete time

$\mathrm{n}, \mathrm{B}$ : the quadratic form matrix.

$b_{\mathrm{km}}$ : the elements of this matrix. 
The following quotient of quadratic forms of signal samples is recognized to be a general form for frequency deviation measurement algorithms.

$$
\Delta \hat{f}=\frac{\sum_{K=0}^{N-1} \sum_{m=0}^{N-1} \bar{a}_{k m} v_{n-k} v_{n-m}}{\sum_{K=0}^{N-1} \sum_{m=0}^{N-1} b_{k m} v_{n-k} v_{n-m}}=\frac{K F \bar{A}}{K F B}
$$

For simplicity, the electrical angle deviation estimate is used instead of frequency deviation estimate. Form Equation (14), the following equation can be given:

$$
\begin{aligned}
V n & =v \cos (\omega n \Delta t+\phi) \\
& =v \cos (n d+\phi)
\end{aligned}
$$

It is noted that, the electrical angel deviation $\Delta \mathrm{d}$ is proportional to the deviation of frequency since

$$
\Delta d=\Delta \omega . \Delta t=2 \pi \Delta f . \Delta t
$$

and it is updated to be

whe

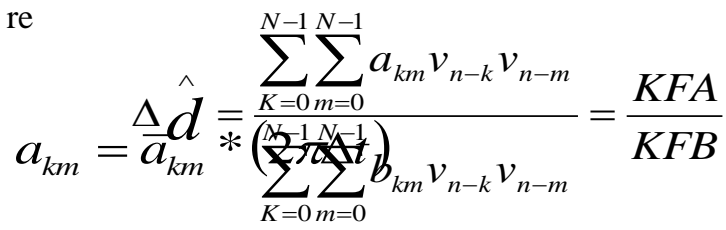

This

expression is made constant in time and real for all frequency deviations of sinusoidal signal. This is achieved by:

1- Imposing constrains on the coefficients of the quadratic forms.

2- Applying tailor's expansion on the quadratic forms to give a quotient of two frequency polynomial.

3- The coefficients of the polynomials can be chosen so that the quotient becomes equal to the value of signal frequency deviation.

$$
V a=V b=V c
$$

The estimate of the electrical angle deviation, given by Equation (19) now becomes:

and by the general delimitations of;

$$
\begin{gathered}
\omega_{0}=\mathrm{a} \cdot \mathrm{V}_{\mathrm{n}-2}+\mathrm{b} \cdot \mathrm{V}_{\mathrm{n}-3}+\mathrm{c} \cdot \mathrm{V}_{\mathrm{n}-7}+\mathrm{d} \cdot \mathrm{V}_{\mathrm{n}-12} . \\
\omega_{1}=\mathrm{a} \cdot \mathrm{V}_{\mathrm{n}-1}+\mathrm{b} \cdot \mathrm{V}_{\mathrm{n}-2}+\mathrm{c} \cdot \mathrm{V}_{\mathrm{n}-6}+\mathrm{d} \cdot \mathrm{V}_{\mathrm{n}-11} \\
\delta_{0}=\mathrm{e} \cdot \mathrm{V}_{\mathrm{n}-2}+\mathrm{f} \cdot \mathrm{V}_{\mathrm{n}-3}+\mathrm{g} \cdot \mathrm{V}_{\mathrm{n}-7} \cdot \\
\wedge \hat{\boldsymbol{d}}=\frac{v_{n} \cdot \omega_{0}-v_{n-1} \cdot \omega_{1}}{v_{n} \cdot \delta_{0}-v_{n-1} \cdot \delta_{1}} \\
\delta_{1}=\mathrm{e} \cdot \mathrm{V}_{\mathrm{n}-1}+\mathrm{f} \cdot \mathrm{V}_{\mathrm{n}-2}+\mathrm{g} \cdot \mathrm{V}_{\mathrm{n}-6} .
\end{gathered}
$$

where $a, b, c, d, e, f$ and $g$ are the coefficients of the quadratic froms. For the coefficient constraints expressed $\mathrm{c}=0.05$ and $\mathrm{d}=0.01$, the following values for the coefficients of quadratic froms are deduced;

$$
\begin{array}{ll}
a=-1.044303503155235 & b=0.5282386282938 \\
e=0.78543321540189 & F=-1.05813678372674 \\
g=-0.03443924221845 &
\end{array}
$$

The sampling rate for the small frequency deviation algorithm is chosen to be 16 samples/cycle, then the nominal electric angle for this case is equal to $\mathrm{d}_{0}=\pi / 8$. The algorithm when implemented is simple, fast and accurate. No look-up tables/or iterations are necessary to calculate the correction. The algorithm is well performed without noise simplification.

\section{FAULT RESPONSE WITHOUT PROTECTION EQUIPMENT}

The MATLAB "Simulink" can be as shown in Figure 4, is used to obtain the steady state solution of the system. The parameters of the system referring to the induction generator bases are as follows; referred to Figure 1.

$$
\begin{array}{ll}
\mathrm{Rt}=0.0094 & \mathrm{lt}=0.0140 \\
\mathrm{RL}=0.7964 & \mathrm{lL}=0.4995 \\
\mathrm{Re}=0.0090 & \mathrm{Le}=0.0061 \\
\mathrm{Cx}=1.0070 & \mathrm{rn}=\mathrm{ln}=0
\end{array}
$$

The generator is initially operating at rated voltage and rated current. The input mechanical power, pm is 0.9271 $\mathrm{p}-\mathrm{u}$ and is assumed to remain constant during system abnormalities. The load and the capacitance have been computed to reset the system.

\subsection{InfluenCe OF 3 PhaSe-to-Ground FAult}

For a three-phase-to-ground or a three-phase fault at point $F$ in Figure 1, at the instant of fault, the capacitors and the load are short circuited.

The simulation results are show in figure 5 . It can be seen that large line currents flow initially following the fault inception. As consequence of the rapid change in currents. 


\subsection{INFLUENCE OF LINE-TO-LINE FAULT}

For a fault on phases $\mathrm{b}$ and $\mathrm{c}$ at point $\mathrm{F}$ in figure 1 .

$$
V_{b}=V_{c}
$$

Since the line-to-line fault does not involve the ground we have

$$
\begin{gathered}
I_{0}=0 \\
V_{a}+V_{b}+V_{c}=0
\end{gathered}
$$

Therefore

$$
V_{b}=V_{c}=-V_{a} / 2
$$

\subsection{INFLUENCE OF SINGLE-LINE-TO-GROUND FAULT}

For a fault on phase a at point F, Figure (1).

$$
V_{a}=0
$$

From the Figure (8) it is clear that the momentary short circuit current $\left(I_{a}\right)$ reaches $(830 \mathrm{~A})$ then decays to $(425 \mathrm{~A})$ in two cycle. Phase a lost excitation but phases b and $\mathrm{c}$ still have excitation causing high current in phase a.

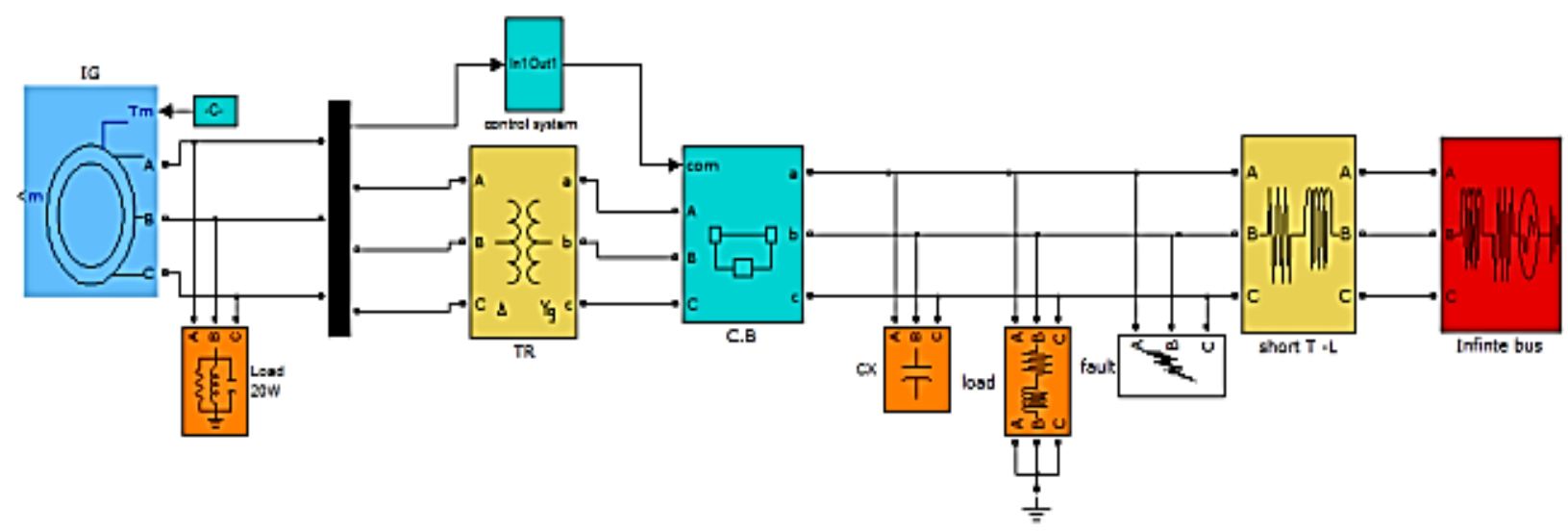

Figure 4. The studied system in the matlab Simulink

It can be seen that from Fig.6 the short circuit current (Ib) peaked at (630A) does not decay and is opposite in sign to (Ic) for a few cycles.

\section{4 .3 INFLUENCE OF DOUBLE-LINE-TO-GROUND FAULT}

For a fault on phases $\mathrm{b}$ and $\mathrm{c}$ at point $\mathrm{F}$ as shown in figure 1 ,

$$
V_{b}=V_{c}=0
$$

From Figure (7) are is shown that the unfault phase current $\left(I_{a}\right)$ is about $(700 \mathrm{~A})$. It is larger than the faulted phase current $\left(\mathrm{I}_{\mathrm{b}}\right.$ and $\left.\mathrm{I}_{\mathrm{c}}\right)$. This effect is caused by the loss of excitation of phase's b and c. It is noted that the momentary current is dependent on the short circuit angle. Therefore, the maximum values of the short circuit currents observed are not definite. 



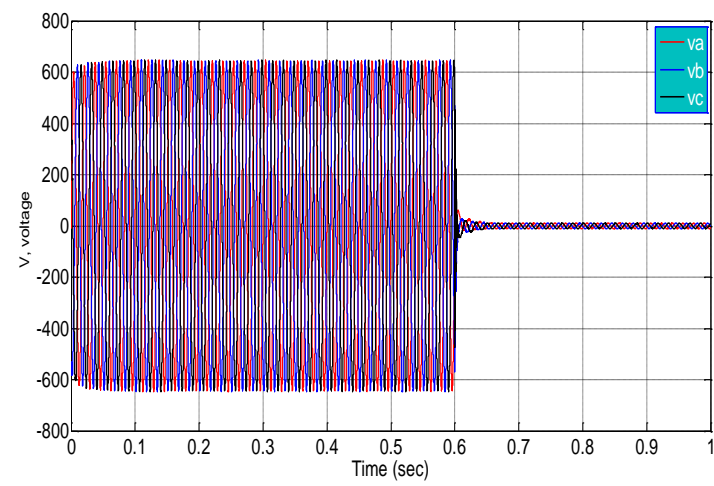

(a)

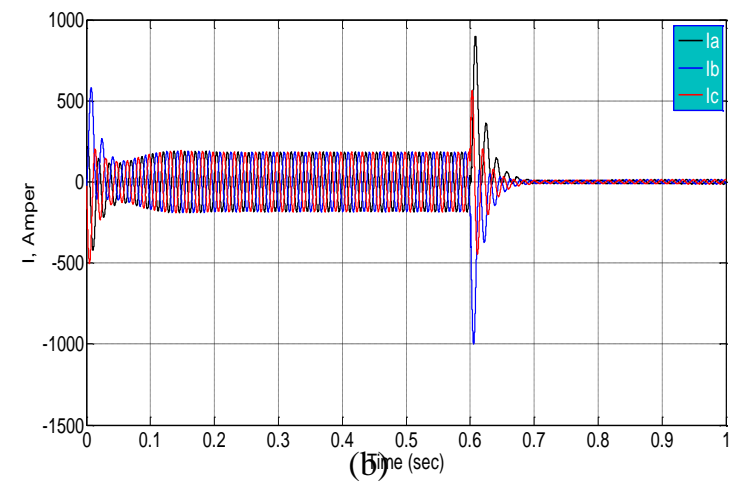

Figure5.Voltage and current wave form when a 3Phase fault occurs at Point F

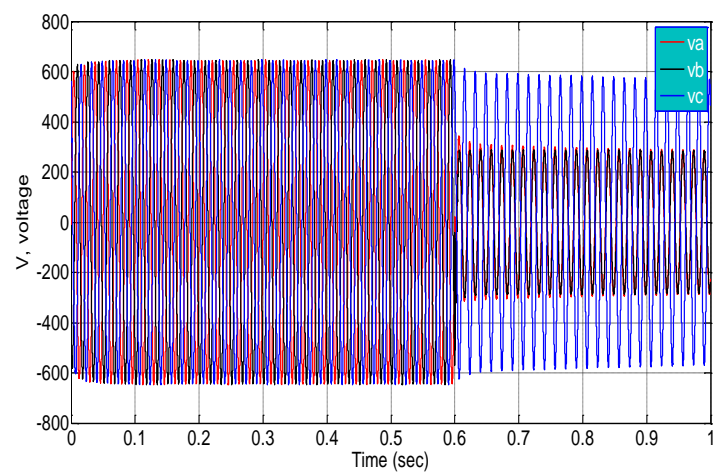

(a)

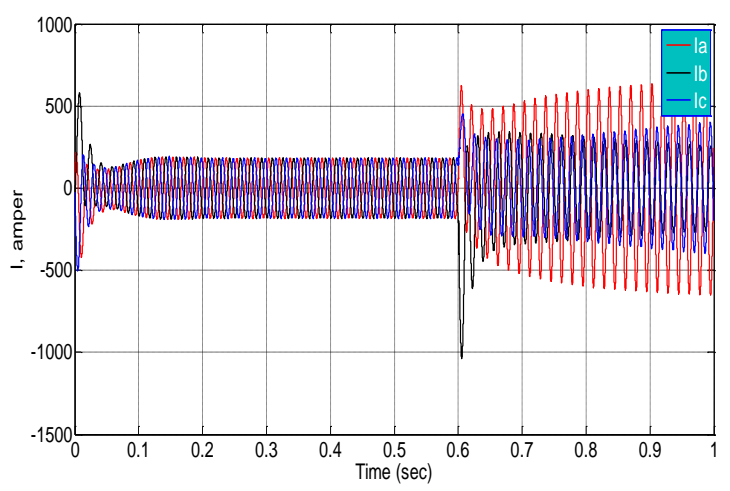

(b)

Figure 6. Voltage and current wave form when a Line-to-Line fault occurs at point $\mathrm{F}$ 


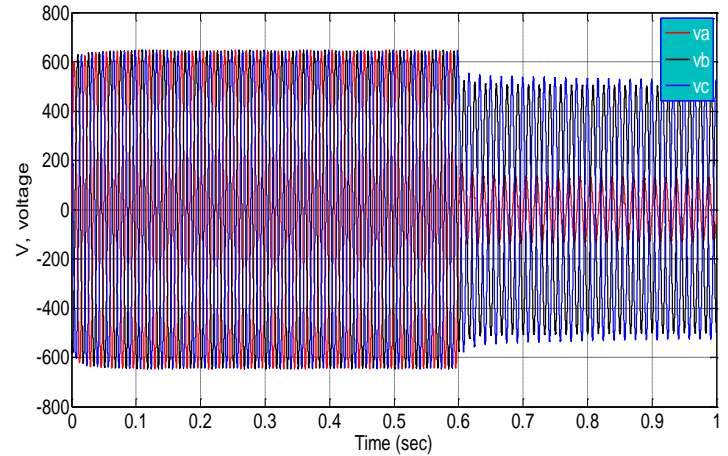

(a)

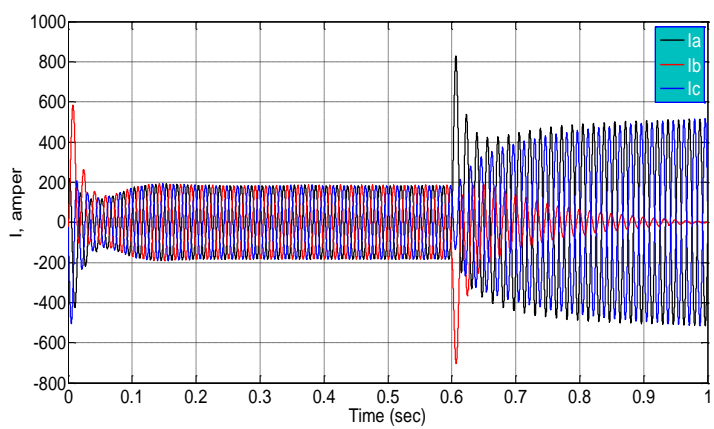

(b)

Figure 8. Voltage and current wave form when a single Line-to-Ground fault occurs at Point F

\section{FAULT RESPONSE WITH PROTECTION SCHEMES}

The simulation results are shown in Figures 9, 10. In Figure 9-a large line currents flow initially following the fault inception can be seen while there is no visible effect to the circuit breaker. Figure 9-b shows that the effects of the over current relay when it is set at 165 to $187 \%$ of rated current of the machine. The circuit breaker is disconnected in the system, and the overcurrent relay is activated. Control can be gained over circuit breaker if $\mathrm{K}=0$ or $\mathrm{K}=1$. The simulation results are shown in Figure 10.

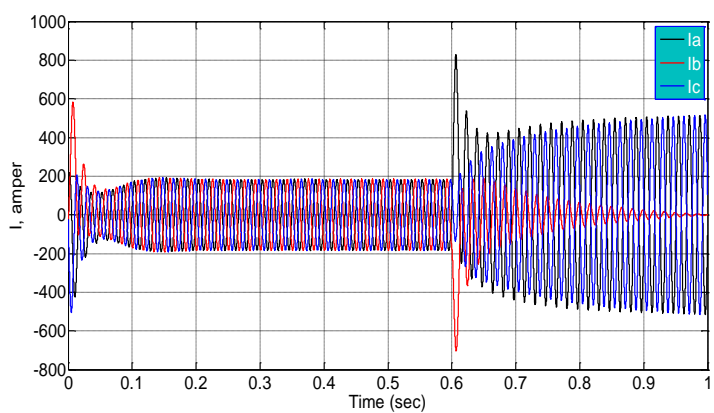

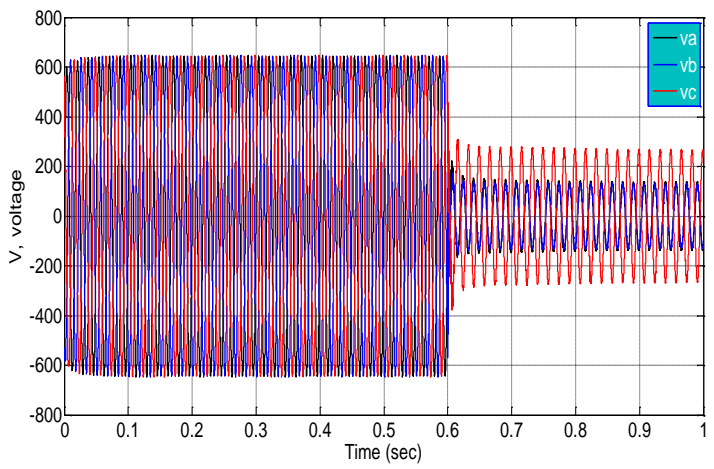

(a)

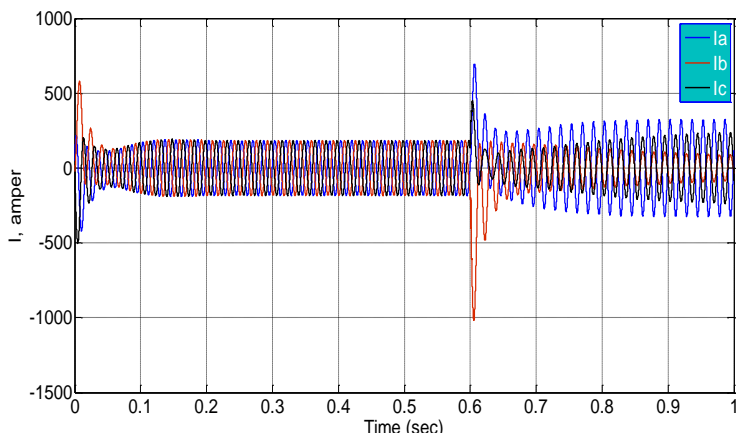

(b)

Figure7. Voltage and current wave form when a Double Line-to-Ground fault occurs at Point F

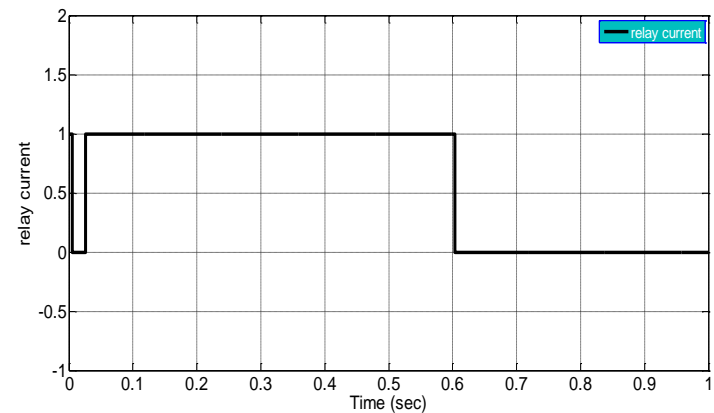

(b)

Figure 9. Effect of circuit breaker operation on the over-current and under voltage relays 


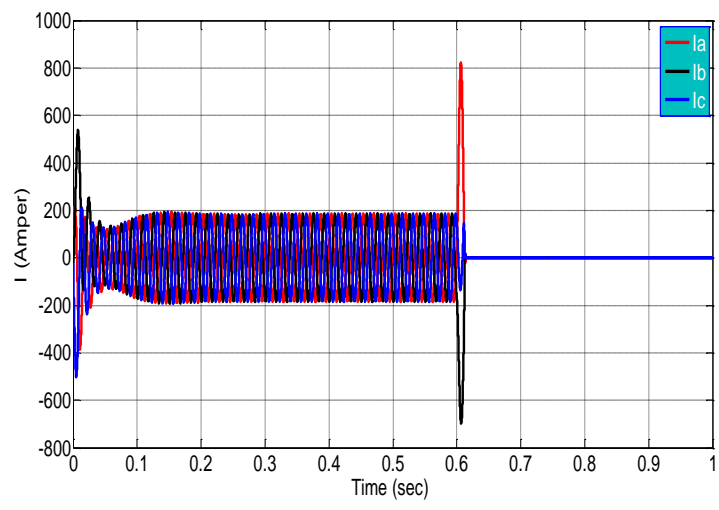

(a)

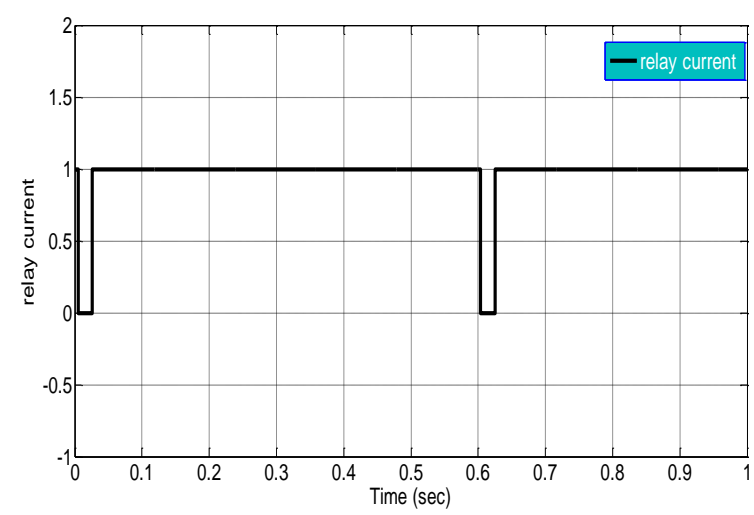

(b)

Figure 10. Effect of circuit breaker operation on the overcurrent relay

\section{CONCLUSION}

The transient response of a grid connected constant speed SCIG based wind turbine along with its protection scheme is addressed. Different symmetrical and unsymmetrical faults experienced on SCIG have been conducted. The results show that the current increases rapidly at fault incidence and exceed the nominal current value (1 per unit). Consequently, the generator circuit must be protected against the current increase. Simulation results show that the amplitude of transient voltage is reduced when the fault occurs. In a trail to protect the generator circuit, a four-sample protection current estimation method is employed in this paper to properly design the generator protection scheme. Overcurrent protection is developed in this work. the following points can be concluded.

- The squirrel cage induction generator cannot withstand sustained faults but it can handle with the wind fluctuation.
- Although of the advantages of SCIG, the majority of the literature points to DFIG. So, this paper gives more attention to SCIG.

- The analysis of the induction generator with the presented protection gives good results and it is recommended to keep using such cheap and simple generators.

- The over current is important for protecting the induction generator from the transient short circuit which may causes great damage and the whole system instability.

\section{REFERENCES}

[1] A. A. Mohamed, "Study of Interconnecting Issues of Photovoltaic /Wind Hybrid System with Electric Utility Using Artifical Intelligence", $\mathrm{PhD}$ Thesis, faculty of Engineering, Minia University Egypt, 2006.

[2] E. M. Elhaji, "Impact of Wind Turbine on Power System Voltage Stability," M.Sc. Thesis Department of Electrical and Computer Engineering Graduate School Southern Illineis University Corbondale, May, 2011.

[3] M. Godoy, A. Simoes, and F. A Farret," Renewable Energy Systems Design and Analysis with Induction generators, "CRC press, Boca Raton, FL, 2004.

[4] J. D. Balley,"Factors Influencing the Protection of Small-to-Medium Size Induction Generators," IEEE Transaction on Industry Applications, Vo1.24, No.5, pp.955-964, 1988.

[5] A. A. Sattar, N. H. Saad, M. Z. Shams ElDein, "Dynamic Response of Doubly Fed Induction Generator Variable Speed Wind Turbine under Fault" Ain Shams University, Egypt, 2008.

[6] Krisztina Leban, "Doubly Fed Induction Generator Fault Simulation," Institute of Energy Technology Aalborg, 2009.

[7] Hossam M. Attia," Modelling and Protection of Induction Generator Connected to Power Network," M.S $S_{C}$ Ain-Shams University, Egypt, 1994.

[8] X. S. Chen, A. J. Flechsig, c. w. pang, and L. M. Zhuang, "Digital Modelling of An Induction Generator," IEEE International, Seattle University, Washington, 1991. 
